\title{
Thermal Chemistry of Bicyclo[4.2.0]oct-2-enes
}

David C. Powers, Phyllis A. Leber,* Sarah S. Gallagher, Andrew T. Higgs, and

Lynne A. McCullough

Department of Chemistry, Franklin \& Marshall College, Lancaster, Pennsylvania 17604-3003

\section{Table of Contents}

Figure S1, ${ }^{2} \mathrm{H}-\mathrm{NMR}$ spectra of 7- $d$-Bicyclo[4.2.0]oct-2-enes (7-X- $d$-1 and 7-n- $d$-1) and

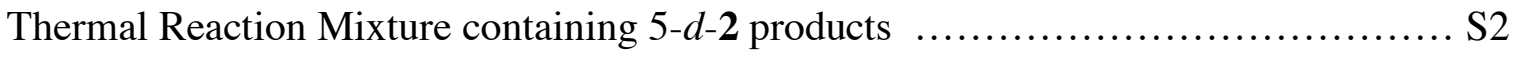

Table S1, GC-Based Kinetic Data for Thermal Reaction of $\mathbf{1}$ at $275^{\circ} \mathrm{C}$, and

Figure S2, First-order Kinetic Plot for Thermal Reaction of 1 at $275^{\circ} \mathrm{C} \ldots \ldots \ldots \ldots \ldots . . . . . .53$

Table S2, GC-Based Kinetic Data for Thermal Reaction of $\mathbf{1}$ at $300{ }^{\circ} \mathrm{C}$, and

Figure S3, First-order Kinetic Plot for Thermal Reaction of 1 at $300{ }^{\circ} \mathrm{C} \ldots \ldots \ldots \ldots \ldots . . . .54$

Table S3, GC-Based Kinetic Data for Thermal Reaction of $\mathbf{1}$ at $315^{\circ} \mathrm{C}$, and

Figure S4, First-order Kinetic Plot for Thermal Reaction of 1 at $315^{\circ} \mathrm{C} \ldots \ldots \ldots \ldots \ldots . . . . . . .55$

Table S4, Temperature-Dependent Concentration Data for Overall Loss of $\mathbf{1}$, and

Figure S5, Arrhenius Plot for Thermal Reaction of 1 ............................ 6

Figure S6, Sample GC Chromatogram for Thermal Reaction of $1 \ldots \ldots \ldots \ldots \ldots \ldots \ldots \ldots . . . \ldots 7$ 

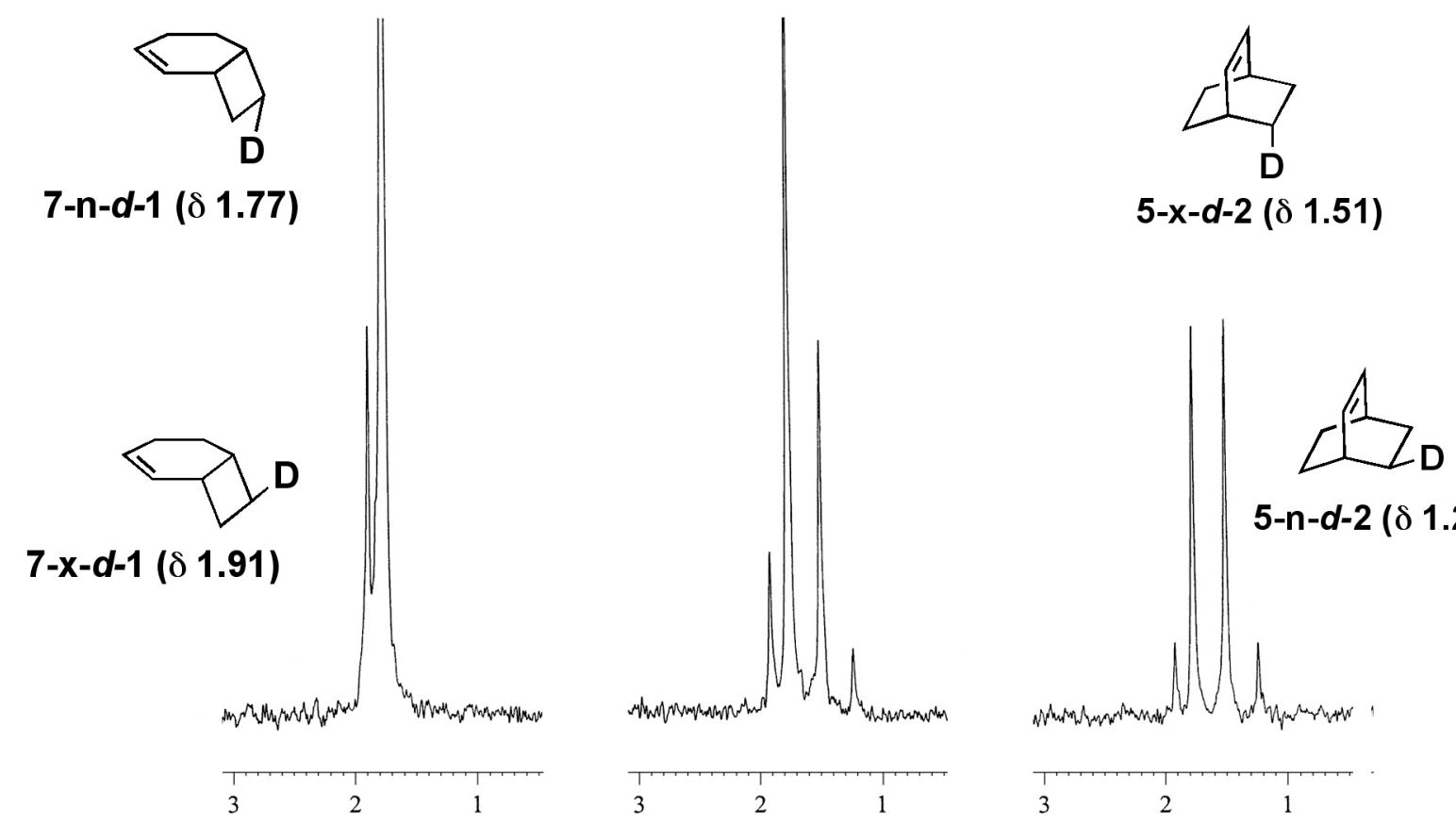

$5-n-d-2$ ( $\delta$ 1.24)

Figure S1. ${ }^{2} \mathrm{H}-\mathrm{NMR}$ spectra of 7- $d-\mathbf{1}$ (left) and of thermal reaction mixtures of 7- $d$-bicyclo[4.2.0]oct-2enes (7-X- $d-\mathbf{1}$ and 7-n- $d-\mathbf{1})$ and 5- $d-2$ products (center, after $1082 \mathrm{~min}$ at $300{ }^{\circ} \mathrm{C}$; right, after $1770 \mathrm{~min}$ ). 
Table S1. GC-Based Kinetic Data for Thermal Reaction of 1 at $275^{\circ} \mathrm{C}$ (concentration expressed as mole fraction)

\begin{tabular}{|c|c|c|c|}
\hline $\operatorname{time}(\mathrm{s})$ & 1 & 2 & 1,3-cyclohexadiene \\
\hline 0 & 1.000 & 0 & 0 \\
\hline $56,835.0$ & 0.940 & 0.033 & 0.028 \\
\hline $108,345.0$ & 0.799 & 0.057 & 0.144 \\
\hline $168,604.8$ & 0.736 & 0.086 & 0.178 \\
\hline $249,032.4$ & 0.676 & 0.124 & 0.200 \\
\hline
\end{tabular}

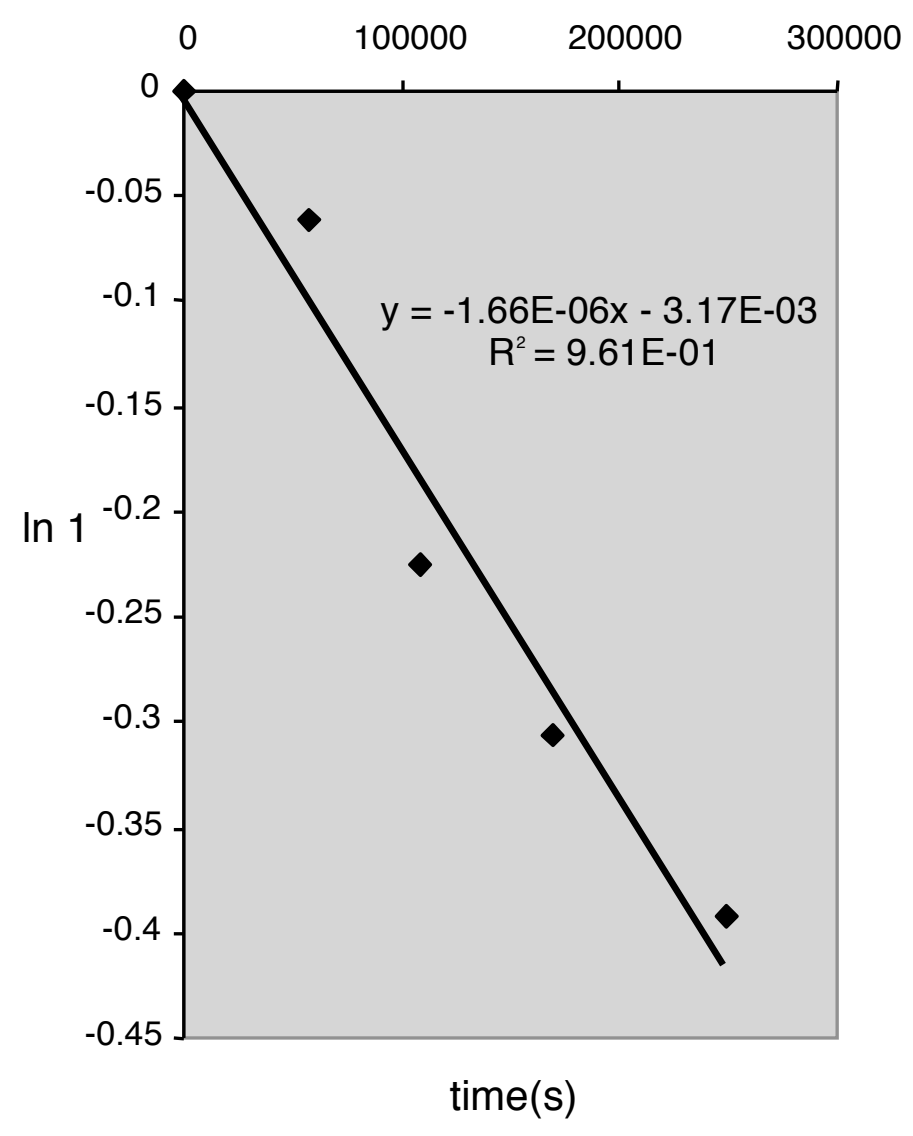

Figure S2. Kinetic Plot for Thermal Reaction of $1\left(275^{\circ} \mathrm{C}\right)$ 
Table S2. GC-Based Kinetic Data for Thermal Reaction of 1 at $300^{\circ} \mathrm{C}$ (concentration expressed as mole fraction)

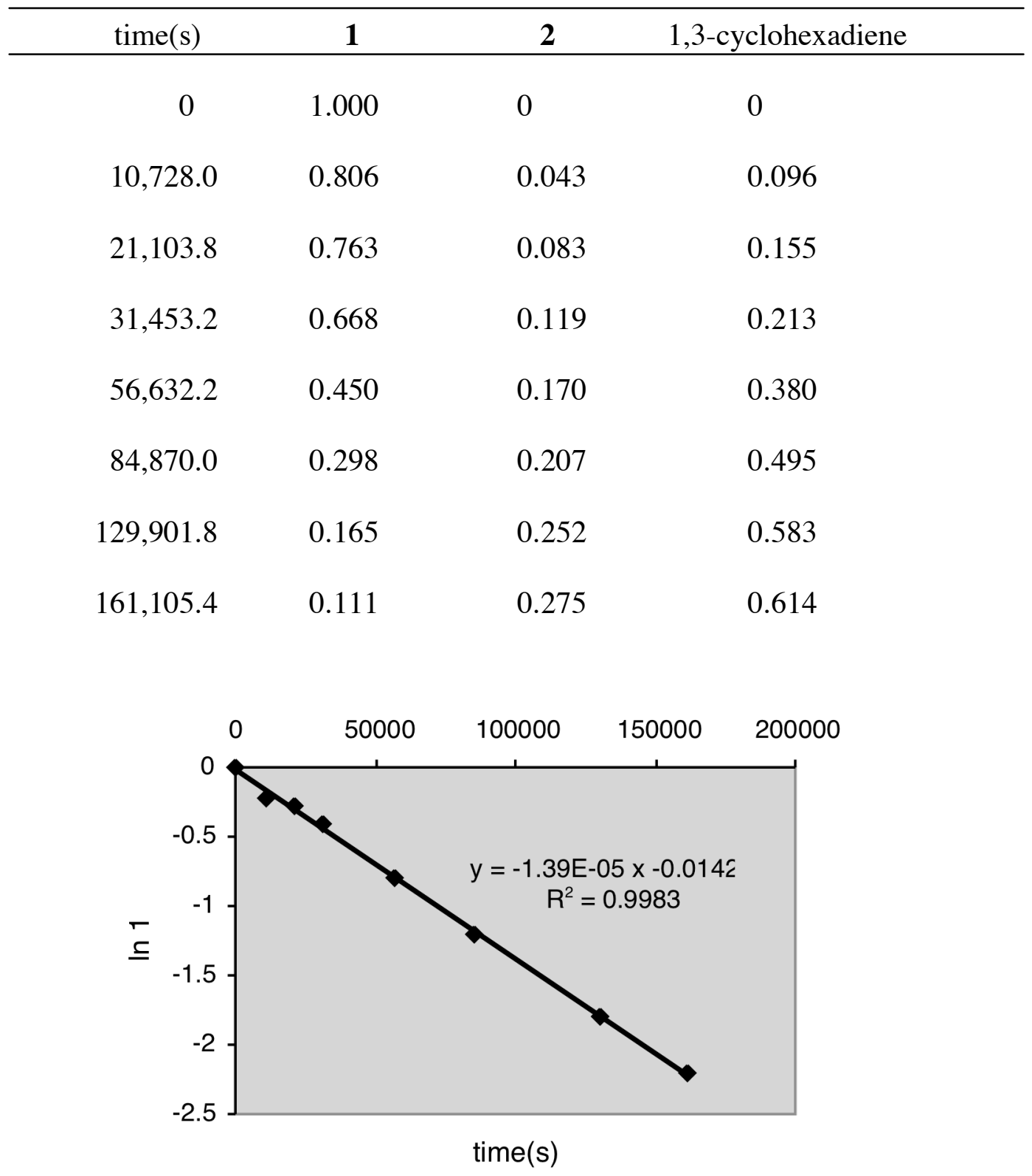

Figure S3. Kinetic Plot for Thermal Reaction of $1\left(300{ }^{\circ} \mathrm{C}\right)$ 
Table S3. GC-Based Kinetic Data for Thermal Reaction of 1 at $315^{\circ} \mathrm{C}$ (concentration expressed as mole fraction)

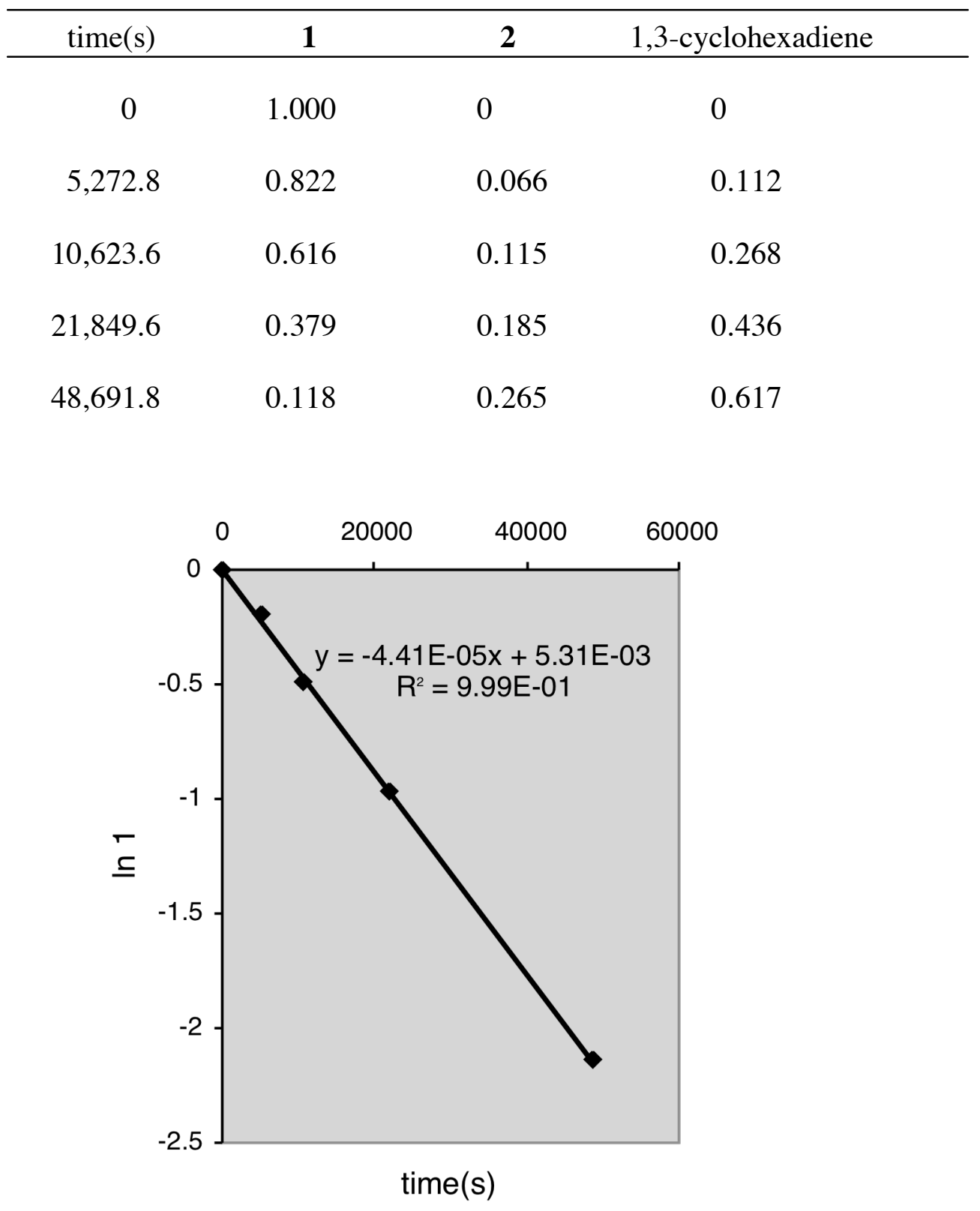

Figure S4. Kinetic Plot for Thermal Reaction of $1\left(315^{\circ} \mathrm{C}\right)$ 
Table S4. Temperature-Dependent Concentration Data for Overall Loss of 1

\begin{tabular}{crrrr}
\hline temp $\left({ }^{\circ} \mathrm{C}\right)$ & $\mathrm{T}(\mathrm{K})$ & $1 / \mathrm{T}\left(\mathrm{K}^{-1}\right)$ & $\mathrm{k}_{0}\left(\mathrm{~s}^{-1}\right)$ & $\log \mathrm{k}_{0}$ \\
\hline 275 & 548 & $1.825 \times 10^{-3}$ & $1.70 \times 10^{-6}$ & -5.770 \\
300 & 573 & $1.745 \times 10^{-3}$ & $1.39 \times 10^{-5}$ & -4.857 \\
315 & 588 & $1.701 \times 10^{-3}$ & $4.41 \times 10^{-5}$ & -4.356
\end{tabular}

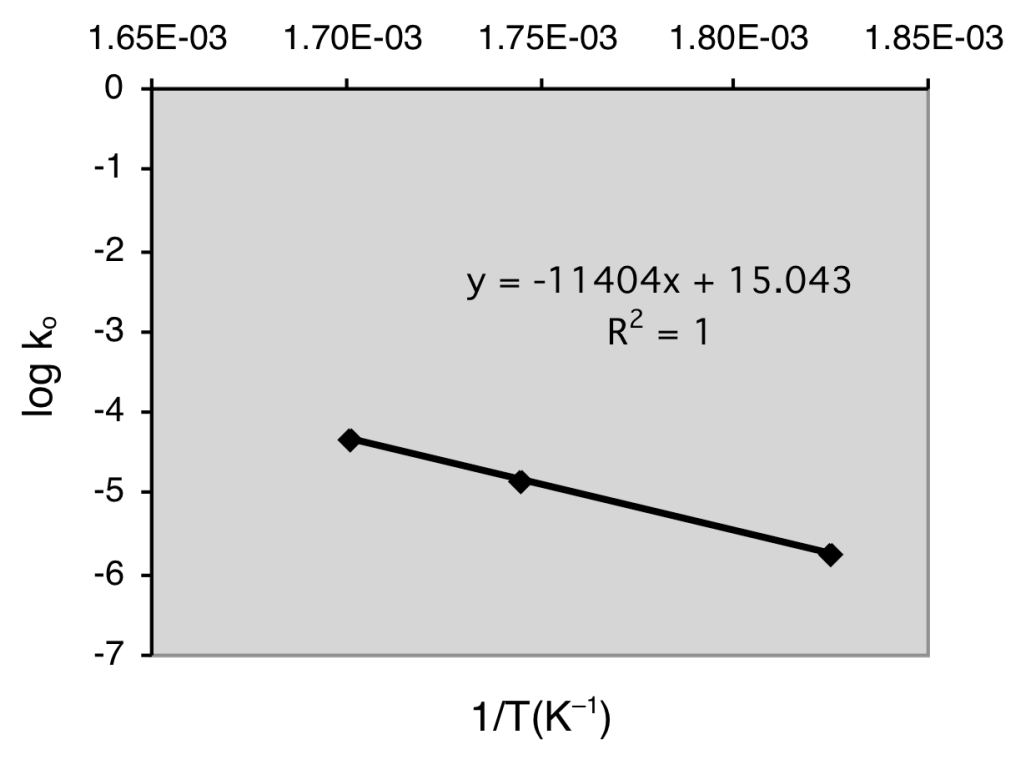

Figure S5. Arrhenius Plot for Thermal Reaction of 1 


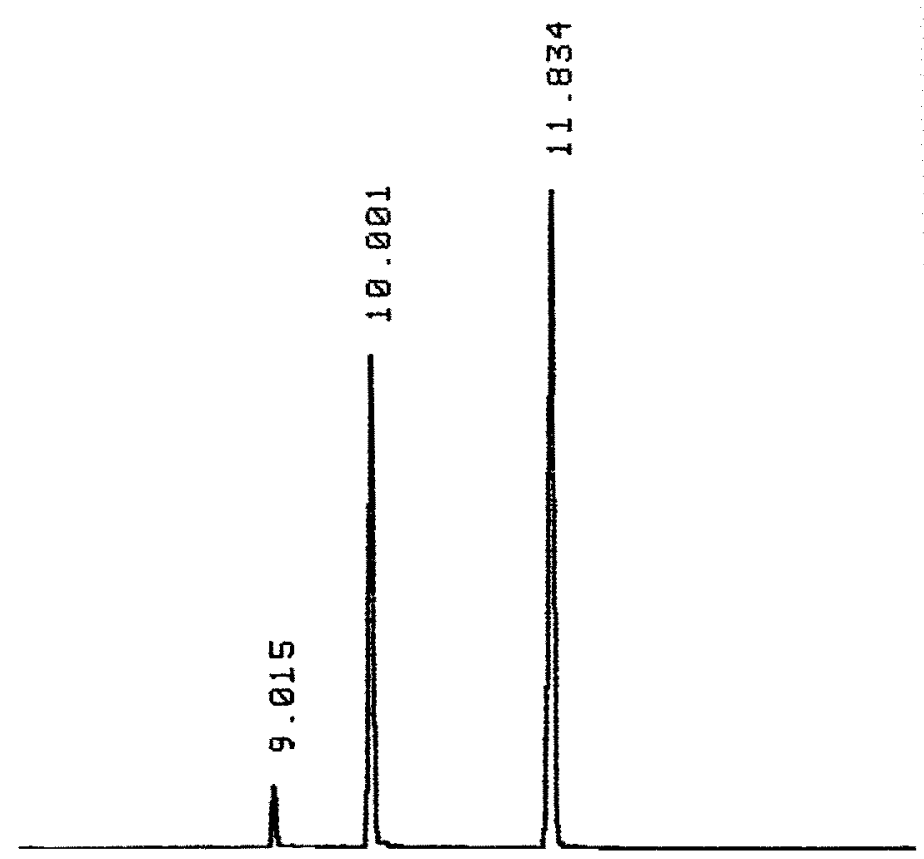

Figure S6. Sample GC Chromatogram for Thermal Reaction of $\mathbf{1}$ in the following Elution Order: Bicyclo2.2.2] oct-2-ene (2), Bicyclo[4.2.0]oct-2-ene (1), and internal standard cyclooctane. 